\title{
Structural Bioinformatics of the Interactome
}

\author{
Donald Petrey ${ }^{\star}$ and Barry Honig ${ }^{*}$ \\ *Department of Biochemistry and Molecular Biophysics, Center for Computational Biology and \\ Bioinformatics, Department of Systems Biology, Howard Hughes Medical Institute, Columbia \\ University, 1130 St. Nicholas Ave., Room 815, New York, NY 10032
}

\begin{abstract}
The last decade has seen a dramatic expansion in the number and range of techniques available to obtain genome-wide information, and to analyze this information so as to infer both the function of individual molecules and how they interact to modulate the behavior of biological systems. Here we review these techniques, focusing on the construction of physical protein-protein interaction networks, and highlighting approaches that incorporate protein structure which is becoming an increasingly important component of systems-level computational techniques. We also discuss how network analyses are being applied to enhance the basic understanding of biological systems and their disregulation, and how they are being applied in drug development.
\end{abstract}

\section{INTRODUCTION}

The volume of diverse data becoming available to a biologist is transforming the way biological research is carried out. In contrast to a reductionist approach aimed at deep understanding of individual systems, this "data revolution" has enabled the prediction of function through the use of statistical, information theoretic and machine learning techniques. This integrated and large-scale approach has dramatically increased the number of functional inferences that can be made, allowing computational construction of genomewide networks, or "interactomes". It is becoming increasingly clear that interactome-level descriptions of molecular function are necessary for a complete understanding of the nature of complex traits and diseases, revealing multiple, synergistic causes for the same phenotype.

Largely due to a dearth of experimental knowledge on the appropriate scale, molecular structure has played little role in these developments. Without structure however, an important dimension in the understanding of molecular function is missing; especially a connection between proposed function and the mechanism by which it is carried out or how that mechanism may be disrupted by disease-associated mutations (51). Advances in structural bioinformatics, including new perspectives on protein fold "space" (143, 154, 197), have led to improved methods of correlating functional relationships with structural similarity. Here we review bioinformatics approaches to the construction of interactomes, with a focus on recent developments in systems-level computational approaches that

*Corresponding authors: Barry Honig, Phone: (212) 851-4651, Fax: (212) 851-4650, bh6@ columbia.edu. Donald Petrey, Phone: (212) 851-4656, Fax: (212) 851-4650, dsp18@ columbia.edu. 
incorporate molecular structure. These techniques allow the use of structure without the need for a complete atomic level description, paving the way for the use of molecular structure on an unprecedented scale.

At its most abstract, an interactome is a collection of dots connected by lines, which can represent different things depending on the type of interactome being studied (e.g. signaling, transcriptional, metabolic). The list of interactomes required to describe a biological systems is growing (RNA/RNA, RNA/DNA). Moreover, different interactomes are not independent of each other, and are dynamic in nature with dots/lines appearing and disappearing over time and depending on different conditions. In this review, we will provide some examples of the resources currently available to construct these complex, interdependent and dynamic networks, primarily focusing on interactomes consisting of physical protein-protein interactions (PPIs) unless otherwise indicated. While the construction of a graph representing an interactome is an achievement in itself, it is not always clear how this graph representation translates into basic biological or medical knowledge. However, the use of molecular structure on a large scale, even when the underlying data include potentially error-containing computational structural models, appears to have come of age, and is beginning providing valuable clues to function that are similar in accuracy and coverage to high-throughput (HT) experimental evidence and is facilitating the translation of interactome knowledge to a more complete understanding of biological systems and potential therapies.

\section{BUILDING INTERACTOMES}

\section{Non-structural evidence}

The data that enables the computational study of interactomes independent of molecular structure is derived primarily from high-throughput experiments. Advances in sequencing technologies and other HT techniques have made available large datasets of genomic (32, $145)$, co-expression (12), PPIs $(49,65,156,195)$, and proteomic $(66,167)$ measurements for multiple organisms. The methods for functional and physical interaction prediction based on this data have been extensively reviewed $(55,63,82,119,136,155)$ so we only briefly survey them here.

Genomic data have yielded methods based on the assumption that two proteins with similar evolutionary histories are more likely to interact, either functionally or physically (reviewed in $(37,113)$. Similarity in evolutionary history can be measured by comparing proteins' phylogenetic profiles (142), i.e., vectors whose elements indicate whether the ortholog of a protein is present in a given species. Evolutionary similarity can also be measured by comparing two proteins' phylogenetic trees $(84,85,138,150)$ where here similarity is calculated as the correlation between the matrix of pairwise sequence similarities for all proteins in the two trees.

Given experimental PPI data for the small set of model organisms currently available, sequence searches can be used to predict interactions for other sequenced organisms. That is, if two proteins interact in a given organism, then their orthologs in another organism ("interologs" (127)) are likely to interact as well $(36,78)$. The relative location/order of 
orthologous proteins from two genomes has also been used as the basis of interaction prediction. For example, if two genes are near each other along the DNA sequence in one genome they are more likely to interact if their orthologs in a second genome are also near each other $(35,103,139)$ or if those two genes have been fused to form a multi-domain gene $(46,124)$.

Although expression data have also been used to predict interactomes involving proteinprotein interactions $(14,80)$ co-expression is found to constitute only weak evidence of a physical interaction compared to genomic data (194). However co-expression has been successfully exploited for the construction of other types of interactomes; for example, various clustering algorithms (44) have been used to identify functional modules, i.e., subnetworks in an interactome that are likely to participate in the same biological pathway. Information theory applied to the analysis of expression data for transcription factors has enabled the identification of direct targets of transcriptional regulation (125), i.e. proteins that modulate the regulation of targets by their transcription factors via protein-protein interactions (177), master regulators of disease associated biological pathways $(112,115)$ and peptide motifs mediating PPIs (116). These techniques constitute state-of-the art strategies for identifying signaling networks (6).

\section{Machine learning}

There have been many questions raised regarding the reliability of high-throughput experimental approaches whose origins probably lie in systematic difficulties with the different technologies. Problems can include incomplete coverage, a potentially high percentage of false positives, and a lack of overlap between different datasets generated for the same organisms $(121,136,148,160,165,174)$. A number of attempts have been made to assign confidence scores to interactions derived from HT data $(17,39,89,189)$. Despite their shortcomings, HT data nevertheless appear to be accurate enough that they have successfully enabled the development of methods to construct interactomes using a variety of machine-learning techniques.

HT enables machine-learning approaches by providing sufficiently large datasets to train an algorithm, a process that generally involves identifying which "features" of PPIs in the dataset correlate with true and false components of interactomes. Features used in the different algorithms can include those described above such as sequence similarity (186, $188)$, evolutionary history $(70,190)$ or gene/domain association $(25,159)$. Graph-theoretic approaches have also been used to transfer knowledge from well-covered interactomes (e.g., HT data) to organisms whose interactomes are only sparsely populated (183).

A drawback to the use of such features is that, on their own, they may only provide weak evidence for membership in an interactome. A particularly promising approach to the construction of interactomes enabled by large-scale HT-derived datasets involves machine learning algorithms that combine different sources of information. In general, combining weak evidence for membership in an interactome can result in more successful predictors. Such approaches include Bayesian classifiers (18, 81, 112, 118, 194, 195), decision tree approaches (169) support vector machines (SVMs) $(34,101,140)$, random forest classifiers $(26,27,45)$, and a host of other techniques $(13,20,74,122,126,187)$. 


\section{Structural evidence}

The types of information used to predict PPIs using machine learning techniques have the distinct advantage that they can be obtained for nearly all proteins in a genome. This level of coverage has proven to be very difficult to achieve for structural information, despite considerable advances in structural bioinformatics and high-throughput experimental structure determination. Protein structural and functional information is, of course, crucial for the complete understanding of interactomes. For example, in the context of proteinprotein interactions, it is necessary to understand the nature of multi-protein complexes, indicating which interactions are direct and which are mediated by other proteins, a feature which is often not clear with some HT experimental techniques. A structural model of an interaction between three or more proteins can indicate whether all the proteins can interact simultaneously in the complex or whether some of the interactions are mutually exclusive, occurring at different stages of a functional pathway. Of course, such information provides important data about the temporal variability of networks $(2,93)$.

A number of attempts have been made to apply atomic level descriptions of protein structure to genome-wide interaction prediction $(134,179)$ where the starting point is the structures of individual subunits that need to be "docked" together. However, the availability of the highly accurate models of individual subunits, which are generally required if docking approaches are to be successful, is limited. In addition, problems such as the uncertain reliability of methods to evaluate binding free energies from the structure of a complex, the computational cost of sampling different binding modes and the possibility that individual subunits can undergo conformational changes upon complexation, confound the accurate calculation of binding affinities. External sources of information such as distance constraints from nuclear magnet resonance or cryo-electron microscopy have been used to simplify the problem (88) but, overall, it is not clear that genome-wide studies based on docking approaches will be feasible for some time.

The prediction of the structure of protein-protein complexes can be greatly simplified by using experimentally determined structures as "templates". Template-based approaches depend on the assumption that the binding mode between two proteins will be similar to that of a known complex between two other proteins that are similar either in sequence or structure. While there can be variability in the binding modes of sequence/structurally similar proteins $(5,94,104)$, there is a growing body of evidence suggesting that regardless of this variability, there is in general at least one complex in current structural databases that can serve as a reasonable template for a given interaction $(54,107,196)$.

Interaction templates can be used in several ways. For example, a structure-based superposition of models of two query proteins on a template structure involving a proteinprotein complex can be carried out to provide an approximation to the binding mode (60, $135,194)$ sometimes followed by additional structural refinement (163). Alternatively, the sequences of query proteins can be directly aligned on the template itself (158). Given that a model constructed from a template is unlikely to be accurate enough to be evaluated using a physical-chemical approach, evaluation is frequently carried out using methods that are designed to be insensitive to atomic detail, instead examining whether the properties of the modeled interface correlate those observed in known PPIs. Evaluation criteria can include 
sequence similarity (166), the presence of sequence and structural motifs derived from known interactions $(8,87,117)$ and the presence of co-evolving residues $(69,159)$ in the interface.

Machine learning techniques make it possible to combine features such as these with other features to yield a composite prediction scheme. Examples include a combination of sequence and structural similarity between the query and template proteins (72), binding pocket shape (57), and biophysical features such as hydrophobicity and hydrogen bonding potential (73). We recently showed with a Bayesian approach that using structural similarity to provide an approximate model of the binding mode combined with an interaction model evaluation scheme involving multiple empirical features of the modeled interface was an especially strong indicator of a true interaction. The use of structural information in this way yielded an algorithm that performed comparably to the combined use of all other sources of non-structural evidence, thus providing strong evidence that structural information can indeed be productively used on a genome-wide scale.

\section{ANALYZING INTERACTOMES}

As discussed above, there are significant concerns about the reliability of interactomes constructed, necessarily, using HT experimental techniques. However, it is important to understand that the main role of data generated by such techniques is hypothesis generation and that these methods need to be evaluated in light of their role in driving further research. We review here some of the recent work that exploits experimentally and computationally derived databases in studies of the molecular basis of disease, highlighting some cases where three dimensional structure is used.

\section{Network Understanding of Cell Regulation/Disregulation}

A key factor in making the profusion of available data useful is the development of appropriate techniques to analyze them. For example, in the context of cancer, large-scale genome sequencing efforts such as The Cancer Genome Atlas (TCGA), have begun to uncover a considerable degree of heterogeneity in cancer. On average, about fifty genes can be mutated (including well-known cancer drivers), but with many of these unique to any given tumor (173). Moreover, it appears that mutations in cancer driver genes on their own are typically not sufficient for cancer progression (16). Genome-wide association studies indicate that this seems to be true for genetic diseases in general, with a few mutations being easily identifiable as drivers of the disease, while explaining only a small percentage of their heritability (180). There has consequently been shift away from a "one gene-one disease" approach to analyzing cell disregulation towards a network-based approach.

This "network biology" strategy has generated what has been a growing interest $(11,53,76$, $151,172)$. The expectation is that for a given disease a single or small set of disregulated pathways/sub-networks $(19,75)$ will be uncovered, despite different underlying causes. In this scenario, disruption results from rare genetic variants that modify the function of their associated protein product or that interact epistatically with driver genes. Network analysis of disease has been carried out in various ways that have been recently reviewed $(30,95)$. In broad terms (see Figure 1), these approaches start with an interactome (e.g. PPI, regulatory, 
metabolic, constructed using the methods described above), and attempt to find subnetworks within it that are "enriched" in genes associated with a certain phenotype. As with the construction of the interactomes themselves, these approaches are enabled by large-scale experimental datasets (e.g., high-throughput sequencing or expression profiles) which are used as a proxy to represent the phenotype.

Phenotype-associated subnetworks are identified in several ways using techniques from multiple disciplines: analysis of gene expression profiles using information theory (123, $176)$, clustering $(44,137)$; graph theory, where nodes/subnetworks are identified based their topological network properties (e.g., connectedness, betweeness, and other features) (83, $171)$; graph search algorithms $(58)$; and set cover approaches $(96,168)$ that attempt to identify the submodules in a network that are most often associated with a set disease related expression data. Again, multiple types of evidence have been combined using machine learning techniques including Bayesian networks (198) and decision trees (3).

A network biology approach is also beginning to be applied to non-genetic diseases as well; bacterial and viral infection in particular. In this context, it is especially important to understand how pathogens coopt host interactomes, especially PPI networks, during infection. Structural mimicry appears to be an important component of this process (41), with pathogen proteins taking on the shape of a host protein and binding to that protein's partners to activate or inhibit normal host pathways. Computational methods such as those described above are being used to predict host-pathogen interactomes $(7,43)$ with some methods incorporating protein structure (40). These approaches have been used to identify functional submodules in the native host interactomes which are affected by infection (162, 191). This more complete understanding of host-pathogen interactomes is crucial to developing effective drugs targeting the ever-growing problem of multi-drug resistant bacteria.

\section{Adding Structure to Networks}

Understanding how physical interactomes are disrupted in cancer has generated much interest in the network biology of PPIs (59). Classic examples of important physical interactions in the context of cancer (77) include interactions made by oncogenes (e.g., RAS) that drive cell proliferation or interactions that target tumor suppressors for proteolysis (e.g., p53 and MDM2). It has recently been shown that cancer-associated mutations are enriched in protein-protein interfaces (178) with an approach that exploits homology models to enhance the structural coverage of the human proteome. Consequently, a systems-level description of cancer-related pathways combined with a knowledge of protein structure is crucial for understanding the combined effects of multiple mutations and developing effective therapies that target PPI networks (61).

Several efforts have been made recently to incorporate protein structure into large scale computational network biology techniques. As in the construction of interactomes, structural information can provide valuable additional clues in their analysis. Zhang, et al. (192) have developed a method to predict patient outcomes by combining, using a Bayesian approach, co-expression data with a score reflecting the likelihood that a somatic mutation may disrupt an interaction, based on its presence in interacting structures (47). Other groups have used 
structural information to analyze the correlation of topological properties of a protein's position in the interactome with its structural properties, finding that hub proteins have larger accessible area with mutations enriched on the surface (91), and that cancer-related proteins tend to interact with multiple partners at multiple interfaces $(61,86)$. These findings are consistent with the expectation that mutations that disrupt physical interactions regulating interactome behavior are likely to be disease related. On a smaller scale structural modeling has identified new members of function specific subnetworks, suggesting previously unknown interactions related to apoptosis (1) and rhodopsin signaling (92) and clarifying the temporal dynamics of the p53 interactome (164)\}. Structural information has been important in understanding between-species interactomes (reviewed in (50), playing a role in clarifying the functional pathways that are disrupted/manipulated upon viral or bacterial infection (147) and revealing the molecular mechanisms by which infectious organism co-opt the host (41). Protein structure has also begun to play a role in the understanding of signaling (109) and metabolic networks (23).

\section{Drug Development}

An important goal of network-based analyses of naturally occurring interactomes is the prioritization of proteins to be targeted by drugs. Techniques for the analysis of a different set of interactomes, whose nodes are proteins and small molecules, are currently being developed in the drug design process itself and integrated with analyses of naturally occurring interactomes $(9,33,67,146)$. This "network pharmacology" approach is expected to address several important problems in drug design, where ever increasing numbers of drug candidates fail to pass clinical trials (102). In particular, the considerable robustness of biological networks to the removal of single components, as suggested by experiments in model organisms (68) has prompted a shift away from a traditional "one-disease, one-target" approach (129). Analyses of protein/small-molecule interactomes have revealed a remarkable degree of interconnectedness in protein/drug interactomes, and in general it can be expected that a given drug will interact with multiple proteins and a single protein will be the target of multiple drugs $(71,185)$. A systems-level understanding of issues such as these is necessary for a proper understanding of drug efficacy and toxicity $(67,98,141,199)$.

The strategies used to construct and analyze protein-drug interactomes are analogous to those used for biological interactomes, with chemoinformatics taking the place of bioinformatics. Although large-scale screening using detailed drug-protein docking is currently possible (52) chemoinformatics-based approaches do not require atomic level descriptions of small molecules, which are instead represented by "fingerprints", i.e., vectors whose elements reflect biophysical properties of the molecule such as the presence of a particular chemical group (62). Similarities between small molecule fingerprints on their own have been shown to be effective in identifying off-target proteins, as long as the random probability that two small molecules have a given level of similarity is properly taken into account (120). As with biological interactomes, machine learning techniques are becoming more prevalent in analyzing protein-drug interactomes $(130,175)$ and have been used to combine small-molecule similarity with features of the protein such as sequence similarity $(4,21), \mathrm{GO}$ ontology (24), as well as information from large datasets of known protein/small molecule interactions $(29,90,170,184)$. 
Protein structural information has also begun to play a more prominent role in the analysis of protein-drug interactomes (42). In particular, as with biological interactomes, analyses using structural similarity are providing important clues that help identify off-targets and drug repurposing targets that appear to arise from remote evolutionary relationships that are not recognizable by sequence-based techniques, and which may be only local in nature (181). As above, the addition of protein structural information gives a better understanding of the mechanism by which a protein carries out its function, allowing a more complete understanding how bioactive molecules disrupt that function and, for example, of the differential effects of drugs on different patients (110). In particular, there has been much interest in the disruption of physical interactions as a treatment mechanism $(76,79)$. The disruption of PPIs with certain classes of molecules has been shown to be therapeutic and several drugs targeting important interactions have been successfully developed (see (149) for some examples). The availability of a protein structure allows the design of drugs that disrupt interactions using a number of approaches (77), typically involving some type of mimicry of the drug target with its interaction partner.

\section{TOOLS AND RESOURCES FOR NETWORK BIOLOGY}

The last decade has seen a dramatic increase in the exploratory power of bioinformatic techniques and with the proper proxy for a given phenotype (e.g, expression profiles, highthroughput sequencing, etc.), a modern biologist can go from disease cause, to drug targets, to drug without ever leaving their desktop. This process can of course generally be carried out in much less time than it would take to do an experiment while the underlying HT data are becoming cheaper and cheaper to create. There is a considerable literature dedicated to familiarizing a beginner with the available databases and tools both for analyzing biological networks $(33,38,100,132)$ and network pharmacology (105). Much effort has also been put into the development and maintenance of software suites and web-servers that integrate and apply the various tools that are available $(48,56,64)$. These are comprehensive reviews and we add here only a brief description of tools that provide protein structural information.

\section{Protein Structure Resources}

Apart from the main repository for experimentally determined protein structures at the Protein Data Bank (PDB), there are now several databases of computationally modeled structures of single proteins such as ModBase (144) and SWISS-MODEL (153). For PPIs, the "Protein Interfaces, Surfaces and Assemblies" (PISA) database (106) contains the likely biologically relevant quaternary structures of proteins contained in the PDB. A number of groups have compiled interactions predicted based on the bioinformatics and machine learning approaches into publicly available databases including STRING (49), PIPs (128), HIPPIE (152). Databases such as these have broad coverage but do not contain information about the potential binding mode for their predicted interactions.

There are a growing number of databases with structural information for protein interactions at varying levels of coverage and resolution. PrePPI (195), Interactome3D (133), GWIDD (108), IBIS (157) and INstruct (131) are large-scale databases containing complete precalculated 3-dimensional models for a large set of predicted interactions while others are limited to experimentally characterized interactions $(15,182)$. Databases that describe PPIs 
in terms of the specific domains of potentially multi-domain proteins that interact $(97,161)$ and that focus on protein-peptide interactions (22) are also available. Some servers such as Interactome3D, Protinfo-PPC (99), 3D-partner (28) allow the prediction of potential interactions between two arbitrary proteins of known sequence on the fly based on homologous complexes in structural databases.

\section{Conclusion}

The synergy of different disciplines (statistics, mathematical, information theory, graph theory, and technological advances) that has given rise to network biology has been a considerable achievement. Of course, the ultimate explanatory power of network biology, and the ability to translate what is learned into effective therapies with network pharmacology remains to be seen. But even at this early stage, there has been success in some areas, such as understanding the synergistic mechanisms of drug combinations (10, $111)$ and classifying cancer subtypes for accurate patient prognosis $(31,193)$ (to name only some recent examples of an extensive literature describing on-going research in this area (9)). Further, network analyses have been shown to be robust to whether they are done using data from high-throughput experiments or computationally derived interactomes (114), indicating that both are of comparable accuracy. Significantly, the important dimension of protein structure, which is vital for understanding functional mechanisms, is only beginning to be incorporated into these approaches, suggesting that the methods can only get better and should become an increasingly important part of a biologist's toolkit.

\section{Acknowledgments}

This work is supported by National Institutes of Health grants GM030518 and GM094597.

\section{References}

1. Acuner Ozbabacan SE, Keskin O, Nussinov R, Gursoy A. Enriching the human apoptosis pathway by predicting the structures of protein-protein complexes. Journal of Structural Biology. 2012; 179:338-46. [PubMed: 22349545]

2. Agarwal S, Deane CM, Porter MA, Jones NS. Revisiting Date and Party Hubs: Novel Approaches to Role Assignment in Protein Interaction Networks. PLoS Comput Biol. 2010; 6:e1000817. [PubMed: 20585543]

3. Akavia UD, Litvin O, Kim J, Sanchez-Garcia F, Kotliar D, et al. An Integrated Approach to Uncover Drivers of Cancer. Cell. 2010; 143:1005-17. [PubMed: 21129771]

4. Alaimo S, Pulvirenti A, Giugno R, Ferro A. Drug-target interaction prediction through domaintuned network-based inference. Bioinformatics. 2013; 29:2004-08. [PubMed: 23720490]

5. Aloy P, Ceulemans H, Stark A, Russell RB. The relationship between sequence and interaction divergence in proteins. Journal of Molecular Biology. 2003; 332:989-98. [PubMed: 14499603]

6. Aluru M, Zola J, Nettleton D, Aluru S. Reverse engineering and analysis of large genome-scale gene networks. Nucleic Acids Research. 2013; 41

7. Arnold R, Boonen K, Sun MGF, Kim PM. Computational analysis of interactomes: Current and future perspectives for bioinformatics approaches to model the host-pathogen interaction space. Methods (Duluth). 2012; 57:508-18.

8. Aytuna A, Gursoy A, Keskin O. Prediction of protein-protein interactions by combining structure and sequence conservation in protein interfaces. Bioinformatics. 2005; 21:2850-55. [PubMed: $15855251]$ 
9. Azmi AS. Network pharmacology: An emerging field in cancer drug discovery. Current Drug Discovery Technologies. 2013; 10:93-94. [PubMed: 23237671]

10. Azmi AS, Wang Z, Philip PA, Mohammad RM, Sarkar FH. Proof of concept: Network and systems biology approaches aid in the discovery of potent anticancer drug combinations. Molecular Cancer Therapeutics. 2010; 9:3137-44. [PubMed: 21041384]

11. Barabasi A-L, Gulbahce N, Loscalzo J. Network medicine: a network-based approach to human disease. Nat Rev Genet. 2011; 12:56-68. [PubMed: 21164525]

12. Barrett T, Wilhite SE, Ledoux P, Evangelista C, Kim IF, et al. NCBI GEO: archive for functional genomics data sets—update. Nucleic Acids Research. 2013; 41:D991-D95. [PubMed: 23193258]

13. Ben-Hur A, Noble WS. Kernel methods for predicting protein-protein interactions. Bioinformatics. 2005; 21:i38-i46. [PubMed: 15961482]

14. Bhardwaj N, Lu H. Correlation between gene expression profiles and protein-protein interactions within and across genomes. Bioinformatics. 2005; 21:2730-38. [PubMed: 15797912]

15. Bickerton G, Higueruelo A, Blundell T. Comprehensive, atomic-level characterization of structurally characterized protein-protein interactions: the PICCOLO database. BMC Bioinformatics. 2011; 12:313. [PubMed: 21801404]

16. Bozic I, Antal T, Ohtsuki H, Carter H, Kim D, et al. Accumulation of driver and passenger mutations during tumor progression. Proceedings of the National Academy of Sciences. 2010; 107:18545-50.

17. Braun P, Tasan M, Dreze M, Barrios-Rodiles M, Lemmens I, et al. An experimentally derived confidence score for binary protein-protein interactions. Nat Meth. 2009; 6:91-97.

18. Burger L, van Nimwegen E. Accurate prediction of protein-protein interactions from sequence alignments using a Bayesian method. Mol Syst Biol. 2008; 4:1-14.

19. Califano A, Butte AJ, Friend S, Ideker T, Schadt E. Leveraging models of cell regulation and GWAS data in integrative network-based association studies. Nat Genet. 2012; 44:841-47. [PubMed: 22836096]

20. Cannistraci CV, Alanis-Lobato G, Ravasi T. Minimum curvilinearity to enhance topological prediction of protein interactions by network embedding. Bioinformatics. 2013; 29:1199-i209. [PubMed: 23812985]

21. Cao DS, Liu S, Xu QS, Lu HM, Huang JH, et al. Large-scale prediction of drug-target interactions using protein sequences and drug topological structures. Analytica Chimica Acta. 2012; 752:1-10. [PubMed: 23101647]

22. Ceol A, Chatr-aryamontri A, Santonico E, Sacco R, Castagnoli L, Cesareni G. DOMINO: a database of domain-peptide interactions. Nucleic Acids Research. 2007; 35:D557-D60. [PubMed: 17135199]

23. Chang RL, Andrews K, Kim D, Li Z, Godzik A, Palsson BO. Structural Systems Biology Evaluation of Metabolic Thermotolerance in Escherichia coli. Science. 2013; 340:1220-23. [PubMed: 23744946]

24. Chen L, Qian Z, Fen K, Cai Y. Prediction of interactiveness between small molecules and enzymes by combining gene ontology and compound similarity. Journal of Computational Chemistry. 2010; 31:1766-76. [PubMed: 20033913]

25. Chen L, Wu L-Y, Wang Y, Zhang X-S. Inferring protein interactions from experimental data by association probabilistic method. Proteins: Structure, Function, and Bioinformatics. 2006; 62:83337.

26. Chen X-W, Liu M. Prediction of protein-protein interactions using random decision forest framework. Bioinformatics. 2005; 21:4394-400. [PubMed: 16234318]

27. Chen X, Jeong J. Sequence-based prediction of protein interaction sites with an integrative method. Bioinformatics. 2009; 25:585-91. [PubMed: 19153136]

28. Chen Y-C, Lo Y-S, Hsu W-C, Yang J-M. 3D-partner: a web server to infer interacting partners and binding models. Nucleic Acids Research. 2007; 35:W561-W67. [PubMed: 17517763]

29. Cheng F, Zhou Y, Li W, Liu G, Tang Y. Prediction of Chemical-Protein Interactions Network with Weighted Network-Based Inference Method. PLoS ONE. 2012; 7:e41064. [PubMed: 22815915]

30. Cho D-Y, Kim Y-A, Przytycka TM. Chapter 5: Network Biology Approach to Complex Diseases. PLoS Comput Biol. 2012; 8:e1002820. [PubMed: 23300411] 
31. Chuang HY, Lee E, Liu YT, Lee D, Ideker T. Network-based classification of breast cancer metastasis. Molecular Systems Biology. 2007; 3:140. [PubMed: 17940530]

32. Consortium EP. The ENCODE (ENCyclopedia Of DNA Elements) Project. Science. 2004; 306:636-40. [PubMed: 15499007]

33. Csermely P, Korcsmáros T, Kiss HJM, London G, Nussinov R. Structure and dynamics of molecular networks: A novel paradigm of drug discovery: A comprehensive review. Pharmacology \& Therapeutics. 2013; 138:333-408. [PubMed: 23384594]

34. Cui G, Fang C, Han K. Prediction of protein-protein interactions between viruses and human by an SVM model. BMC Bioinformatics. 2012; 13:S5. [PubMed: 22595002]

35. Dandekar T, Snel B, Huynen M, Bork P. Conservation of gene order: a fingerprint of proteins that physically interact. Trends in biochemical sciences. 1998; 23:324-8. [PubMed: 9787636]

36. De Bodt S, Proost S, Vandepoele K, Rouze P, Van de Peer Y. Predicting protein-protein interactions in Arabidopsis thaliana through integration of orthology, gene ontology and coexpression. BMC Genomics. 2009; 10:288. [PubMed: 19563678]

37. de Juan D, Pazos F, Valencia A. Emerging methods in protein co-evolution. Nat Rev Genet. 2013; 14:249-61. [PubMed: 23458856]

38. De Las Rivas J, Fontanillo C. Protein-Protein Interactions Essentials: Key Concepts to Building and Analyzing Interactome Networks. PLoS Comput Biol. 2010; 6:e1000807. [PubMed: 20589078]

39. Deane C, Salwinski L, Xenarios I, Eisenberg D. Two Methods for Assessment of the Reliability of High Throughput Observations. Molecular \& Cellular Proteomics. 2002; 1:349-56. [PubMed: 12118076]

40. Doolittle J, Gomez S. Structural similarity-based predictions of protein interactions between HIV-1 and Homo sapiens. Virology Journal. 2010; 7:82. [PubMed: 20426868]

41. Drayman N, Glick Y, Ben-nun-Shaul O, Zer H, Zlotnick A, et al. Pathogens Use Structural Mimicry of Native Host Ligands as a Mechanism for Host Receptor Engagement. Cell Host \& Microbe. 2013; 14:63-73. [PubMed: 23870314]

42. Duran-Frigola M, Mosca R, Aloy P. Structural Systems Pharmacology: The Role of 3D Structures in Next-Generation Drug Development. Chemistry \& Biology. 2013; 20:674-84. [PubMed: 23706634]

43. Dyer MD, Murali TM, Sobral BW. Supervised learning and prediction of physical interactions between human and HIV proteins. Infection, Genetics and Evolution. 2011; 11:917-23.

44. Eisen MB, Spellman PT, Brown PO, Botstein D. Cluster analysis and display of genome-wide expression patterns. Proceedings of the National Academy of Sciences of the United States of America. 1998; 95:14863-68. [PubMed: 9843981]

45. Elefsinioti A, Saraç ÖS, Hegele A, Plake C, Hubner NC, et al. Large-scale De Novo Prediction of Physical Protein-Protein Association. Molecular \& Cellular Proteomics. 2011; 10

46. Enright AJ, Iliopoulos I, Kyrpides NC, Ouzounis CA. Protein interaction maps for complete genomes based on gene fusion events. NATURE. 1999; 402:86-90. [PubMed: 10573422]

47. Finn RD, Marshall M, Bateman A. iPfam: visualization of protein-protein interactions in PDB at domain and amino acid resolutions. Bioinformatics (Oxford, England). 2005; 21:410-2.

48. Floratos A, Smith K, Ji Z, Watkinson J, Califano A. geWorkbench: an open source platform for integrative genomics. Bioinformatics. 2010; 26:1779-80. [PubMed: 20511363]

49. Franceschini A, Szklarczyk D, Frankild S, Kuhn M, Simonovic M, et al. STRING v9.1: proteinprotein interaction networks, with increased coverage and integration. Nucleic Acids Research. 2013; 41:D808-D15. [PubMed: 23203871]

50. Franzosa EA, Garamszegi S, Xia Y. Toward a three-dimensional view of protein networks between species. Frontiers in Microbiology. 2012; 3

51. Fraser James S, Gross John D, Krogan Nevan J. From Systems to Structure: Bridging Networks and Mechanism. Molecular Cell. 2013; 49:222-31. [PubMed: 23352243]

52. Friesner RA, Banks JL, Murphy RB, Halgren TA, Klicic JJ, et al. Glide: a new approach for rapid, accurate docking and scoring. 1. Method and assessment of docking accuracy. Journal of medicinal chemistry. 2004; 47:1739-49. [PubMed: 15027865] 
53. Furlong LI. Human diseases through the lens of network biology. Trends in Genetics. 2013; 29:150-59. [PubMed: 23219555]

54. Gao M, Skolnick J. Structural space of protein-protein interfaces is degenerate, close to complete, and highly connected. Proceedings of the National Academy of Sciences. 2010; 107:22517-22.

55. Garcia-Garcia J, Bonet J, Guney E, Fornes O, Planas J, Oliva B. Networks of Protein_Protein Interactions: From Uncertainty to Molecular Details. Molecular Informatics. 2012; 31:342-62.

56. Gentleman R, Carey V, Bates D, Bolstad B, Dettling M, et al. Bioconductor: open software development for computational biology and bioinformatics. Genome biology. 2004; 5:R80. [PubMed: 15461798]

57. Giguere S, Marchand M, Laviolette F, Drouin A, Corbeil J. Learning a peptide-protein binding affinity predictor with kernel ridge regression. BMC Bioinformatics. 2013; 14:82. [PubMed: 23497081]

58. Gilman Sarah R, Iossifov I, Levy D, Ronemus M, Wigler M, Vitkup D. Rare De Novo Variants Associated with Autism Implicate a Large Functional Network of Genes Involved in Formation and Function of Synapses. Neuron. 2011; 70:898-907. [PubMed: 21658583]

59. Gonzalez MW, Kann MG. Chapter 4: Protein Interactions and Disease. PLoS Comput Biol. 2012; 8:e1002819. [PubMed: 23300410]

60. Guerler A, Govindarajoo B, Zhang Y. Mapping Monomeric Threading to Protein-Protein Structure Prediction. Journal of Chemical Information and Modeling. 2013; 53:717-25. [PubMed: 23413988]

61. Gulati S, Cheng TMK, Bates PA. Cancer networks and beyond: Interpreting mutations using the human interactome and protein structure. Seminars in Cancer Biology. 2013; 23:219-26. [PubMed: 23680723]

62. Haigh JA, Pickup BT, Grant JA, Nicholls A. Small Molecule Shape-Fingerprints. Journal of Chemical Information and Modeling. 2005; 45:673-84. [PubMed: 15921457]

63. Harrington ED, Jensen LJ, Bork P. Predicting biological networks from genomic data. FEBS Letters. 2008; 582:1251-8. [PubMed: 18294967]

64. Hohman M, Gregory K, Chibale K, Smith PJ, Ekins S, Bunin B. Novel web-based tools combining chemistry informatics, biology and social networks for drug discovery. Drug Discovery Today. 2009; 14:261-70. [PubMed: 19231313]

65. Hooda Y, Kim PM. Computational structural analysis of protein interactions and networks. Proteomics. 2012; 12:1697-705. [PubMed: 22593000]

66. Hoogland C, Mostaguir K, Sanchez J-C, Hochstrasser DF, Appel RD. SWISS-2DPAGE, ten years later. Proteomics. 2004; 4:2352-56. [PubMed: 15274128]

67. Hopkins AL. Network pharmacology: the next paradigm in drug discovery. Nature Chemical Biology. 2008; 4:682-90.

68. Hopkins AL, Groom CR. The druggable genome. Nat Rev Drug Discov. 2002; 1:727-30. [PubMed: 12209152]

69. Hosur R, Peng J, Vinayagam A, Stelzl U, Xu J, et al. A computational framework for boosting confidence in high-throughput protein-protein interaction datasets. Genome biology. 2012; 13:R76. [PubMed: 22937800]

70. Hsin Liu C, Li K-C, Yuan S. Human protein-protein interaction prediction by a novel sequencebased co-evolution method: co-evolutionary divergence. Bioinformatics. 2013; 29:92-98. [PubMed: 23080115]

71. Hu Y, Bajorath J. Compound promiscuity: What can we learn from current data? Drug Discovery Today. 2013; 18:644-50. [PubMed: 23524195]

72. Hue M, Riffle M, Vert J-P, Noble W. Large-scale prediction of protein-protein interactions from structures. BMC Bioinformatics. 2010; 11:144. [PubMed: 20298601]

73. Hui S, Xing X, Bader G. Predicting PDZ domain mediated protein interactions from structure. BMC Bioinformatics. 2013; 14:27. [PubMed: 23336252]

74. Hwang D, Rust AG, Ramsey S, Smith JJ, Leslie DM, et al. A data integration methodology for systems biology. Proceedings of the National Academy of Sciences of the United States of America. 2005; 102:17296-301. [PubMed: 16301537] 
75. Ideker T, Ozier O, Schwikowski B, Siegel AF. Discovering regulatory and signalling circuits in molecular interaction networks. Bioinformatics. 2002; 18:S233-S40. [PubMed: 12169552]

76. Ideker T, Sharan R. Protein networks in disease. Genome Research. 2008; 18:644-52. [PubMed: 18381899]

77. Ivanov AA, Khuri FR, Fu H. Targeting protein-protein interactions as an anticancer strategy. Trends in Pharmacological Sciences. 2013; 34:393-400. [PubMed: 23725674]

78. Izarzugaza J, Juan D, Pons C, Pazos F, Valencia A. Enhancing the prediction of protein pairings between interacting families using orthology information. BMC Bioinformatics. 2008; 9:35. [PubMed: 18215279]

79. Jaeger S, Aloy P. From protein interaction networks to novel therapeutic strategies. IUBMB Life. 2012; 64:529-37. [PubMed: 22573601]

80. Jansen R, Greenbaum D, Gerstein M. Relating Whole-Genome Expression Data with ProteinProtein Interactions. Genome Research. 2002; 12:37-46. [PubMed: 11779829]

81. Jansen R, Yu H, Greenbaum D, Kluger Y, Krogan NJ, et al. A Bayesian networks approach for predicting protein-protein interactions from genomic data. Science. 2003; 302:449-53. [PubMed: 14564010]

82. Jessulat M, Pitre S, Gui Y, Hooshyar M, Omidi K, et al. Recent advances in protein-protein interaction prediction: experimental and computational methods. Expert Opinion on Drug Discovery. 2011; 6:921-35. [PubMed: 22646215]

83. Jordan F, Nguyen T-P, Liu W-c. Studying protein-protein interactionnetworks: a systems view on diseases. BRIEFINGS IN FUNCTIONAL GENOMICS. 2012; 11:497-504. [PubMed: 22908210]

84. Jothi R, Kann MG, Przytycka TM. Predicting protein-protein interaction by searching evolutionary tree automorphism space. Bioinformatics. 2005; $21:$ i241-i50. [PubMed: 15961463]

85. Juan D, Pazos F, Valencia A. High-confidence prediction of global interactomes based on genomewide coevolutionary networks. Proceedings of the National Academy of Sciences. 2008; 105:93439.

86. Kar G, Gursoy A, Keskin O. Human Cancer Protein-Protein Interaction Network: A Structural Perspective. PLoS Comput Biol. 2009; 5:e1000601. [PubMed: 20011507]

87. Kar G, Keskin O, Nussinov R, Gursoy A. Human Proteome-scale Structural Modeling of E2-E3 Interactions Exploiting Interface Motifs. Journal of Proteome Research. 2011; 11:1196-207. [PubMed: 22149024]

88. Karaca E, Bonvin AMJJ. Advances in integrative modeling of biomolecular complexes. Methods (Duluth). 2013; 59:372-81.

89. Karagoz K, Arga KY. Assessment of high-confidence protein-protein interactome in yeast. Computational Biology and Chemistry. 2013; 45:1-8. [PubMed: 23608186]

90. Keiser MJ, Roth BL, Armbruster BN, Ernsberger P, Irwin JJ, Shoichet BK. Relating protein pharmacology by ligand chemistry. Nat Biotech. 2007; 25:197-206.

91. Khurana E, Fu Y, Chen J, Gerstein M. Interpretation of Genomic Variants Using a Unified Biological Network Approach. PLoS Comput Biol. 2013; 9:e1002886. [PubMed: 23505346]

92. Kiel C, Vogt A, Campagna A, Chatr-aryamontri A, Swiatek-de Lange M, et al. Structural and functional protein network analyses predict novel signaling functions for rhodopsin. Mol Syst Biol. 2011; 7

93. Kim PM, Lu LJ, Xia Y, Gerstein MB. Relating three-dimensional structures to protein networks provides evolutionary insights. Science. 2006; 314:1938-41. [PubMed: 17185604]

94. Kim WK, Henschel A, Winter C, Schroeder M. The many faces of protein-protein interactions: A compendium of interface geometry. PLoS Computational Biology. 2006; 2:e124. [PubMed: 17009862]

95. Kim Y-A, Przytycka TM. Bridging the Gap between Genotype and Phenotype via Network Approaches. Frontiers in Genetics. 2013; 3

96. Kim Y-A, Wuchty S, Przytycka TM. Identifying Causal Genes and Dysregulated Pathways in Complex Diseases. PLoS Comput Biol. 2011; 7:e1001095. [PubMed: 21390271]

97. Kim Y, Min B, Yi G-S. IDDI: integrated domain-domain interaction and protein interaction analysis system. Proteome Science. 2012; 10:S9. [PubMed: 22759586] 
98. Kitano H. A robustness-based approach to systems-oriented drug design. Nat Rev Drug Discov. 2007; 6:202-10. [PubMed: 17318209]

99. Kittichotirat W, Guerquin M, Bumgarner RE, Samudrala R. Protinfo PPC: A web server for atomic level prediction of protein complexes. Nucl Acids Res. 2009; 37:W519-25. [PubMed: 19420059]

100. Koh GCKW, Porras P, Aranda B, Hermjakob H, Orchard SE. Analyzing Protein-Protein Interaction Networks $\dagger$. Journal of Proteome Research. 2012; 11:2014-31. [PubMed: 22385417]

101. Koike A, Takagi T. Prediction of protein-protein interaction sites using support vector machines. Protein Engineering, Design \& Selection. 2004; 17:165-73.

102. Kola I, Landis J. Can the pharmaceutical industry reduce attrition rates? Nat Rev Drug Discov. 2004; 3:711-16. [PubMed: 15286737]

103. Koonin EV, Wolf YI, Aravind L. Prediction of the Archaeal Exosome and Its Connections with the Proteasome and the Translation and Transcription Machineries by a Comparative-Genomic Approach. Genome Research. 2001; 11:240-52. [PubMed: 11157787]

104. Korkin D, Davis FP, Sali A. Localization of protein-binding sites within families of proteins. Protein Science. 2005; 14:2350-60. [PubMed: 16081657]

105. Koutsoukas A, Simms B, Kirchmair J, Bond PJ, Whitmore AV, et al. From in silico target prediction to multi-target drug design: Current databases, methods and applications. Journal of Proteomics. 2011; 74:2554-74. [PubMed: 21621023]

106. Krissinel E, Henrick K. Inference of Macromolecular Assemblies from Crystalline State. Journal of Molecular Biology. 2007; 372:774-97. [PubMed: 17681537]

107. Kundrotas PJ, Zhu Z, Janin J, Vakser IA. Templates are available to model nearly all complexes of structurally characterized proteins. Proceedings of the National Academy of Sciences. 2012

108. Kundrotas PJ, Zhu Z, Vakser IA. GWIDD: Genome-wide protein docking database. Nucleic Acids Research. 2010; 38:D513-D17. [PubMed: 19900970]

109. Kuzu G, Keskin O, Gursoy A, Nussinov R. Constructing structural networks of signaling pathways on the proteome scale. Current Opinion in Structural Biology. 2012; 22:367-77. [PubMed: 22575757]

110. Lahti JL, Tang GW, Capriotti E, Liu T, Altman RB. Bioinformatics and variability in drug response: a protein structural perspective. Journal of The Royal Society Interface. 2012; 9:140937.

111. Lee Michael J, Ye Albert S, Gardino Alexandra K, Heijink Anne M, Sorger Peter K, et al. Sequential Application of Anticancer Drugs Enhances Cell Death by Rewiring Apoptotic Signaling Networks. Cell. 2012; 149:780-94. [PubMed: 22579283]

112. Lefebvre C, Rajbhandari P, Alvarez MJ, Bandaru P, Lim WK, et al. A human B-cell interactome identifies MYB and FOXM1 as master regulators of proliferation in germinal centers. Mol Syst Biol. 2010; 6

113. Lewis ACF, Saeed R, Deane CM. Predicting protein-protein interactions in the context of protein evolution. Molecular Biosystems. 2010; 6:55-64. [PubMed: 20024067]

114. Li Y, Xu J, Chen H, Zhao Z, Li S, et al. Characterizing Genes with Distinct Methylation Patterns in the Context of Protein-Protein Interaction Network: Application to Human Brain Tissues. PLoS ONE. 2013; 8:e65871. [PubMed: 23776563]

115. Liang Y, Wu H, Lei R, Chong RA, Wei Y, et al. Transcriptional network analysis identifies BACH1 as a master regulator of breast cancer bone metastasis. Journal of Biological Chemistry. 2012; 287:33533-44. [PubMed: 22875853]

116. Lieber DS, Elemento O, Tavazoie S. Large-Scale Discovery and Characterization of Protein Regulatory Motifs in Eukaryotes. PLoS ONE. 2010; 5:e14444. [PubMed: 21206902]

117. Lin C-Y, Chen Y-C, Lo Y-S, Yang J-M. Inferring homologous protein-protein interactions through pair position specific scoring matrix. BMC Bioinformatics. 2013; 14:S11. [PubMed: 23367879]

118. Lin X, Chen X-w. Heterogeneous data integration by tree-augmented naïve Bayes for proteinprotein interactions prediction. Proteomics. 2013; 13:261-68. [PubMed: 23112070]

119. Liu ZP, Chen L. Proteome-wide prediction of protein-protein interactions from high-throughput data. Protein and Cell. 2012; 3:508-20. [PubMed: 22729399] 
120. Lounkine E, Keiser MJ, Whitebread S, Mikhailov D, Hamon J, et al. Large-scale prediction and testing of drug activity on side-effect targets. NATURE. 2012; 486:361-67. [PubMed: 22722194]

121. Lu LJ, Xia Y, Paccanaro A, Yu H, Gerstein M. Assessing the limits of genomic data integration for predicting protein networks. Genome Research. 2005; 15:945-53. [PubMed: 15998909]

122. Maetschke SR, Simonsen M, Davis MJ, Ragan MA. Gene Ontology-driven inference of proteinprotein interactions using inducers. Bioinformatics. 2012; 28:69-75. [PubMed: 22057159]

123. Mani KM, Lefebvre C, Wang K, Lim WK, Basso K, et al. A systems biology approach to prediction of oncogenes and molecular perturbation targets in B-cell lymphomas. Molecular Systems Biology. 2008; 4:1-9.

124. Marcotte EM, Pellegrini M, Ng HL, Rice DW, Yeates TO, Eisenberg D. Detecting protein function and protein-protein interactions from genome sequences. Science. 1999; 285:751-3. [PubMed: 10427000]

125. Margolin AA, Nemenman I, Basso K, Wiggins C, Stolovitzky G, et al. ARACNE: an algorithm for the reconstruction of gene regulatory networks in a mammalian cellular context. BMC bioinformatics. 2006; 7(Suppl 1):S7. [PubMed: 16723010]

126. Martin S, Roe D, Faulon JL. Predicting protein-protein interactions using signature products. Bioinformatics. 2005; 21:218-26. [PubMed: 15319262]

127. Matthews L, Vaglio P, Reboul J, Ge H, Davis B, et al. Identification of potential interaction networks using sequence-based searches for conserved protein-protein interactions or “interologs". Genome Res. 2001; 11:2120-26. [PubMed: 11731503]

128. McDowall MD, Scott MS, Barton GJ. PIPs: human protein-protein interaction prediction database. Nucleic Acids Research. 2009; 37:D651-D56. [PubMed: 18988626]

129. Medina-Franco JL, Giulianotti MA, Welmaker GS, Houghten RA. Shifting from the single to the multitarget paradigm in drug discovery. Drug Discovery Today. 2013; 18:495-501. [PubMed: 23340113]

130. Melville JL, Burke EK, Hirst JD. Machine Learning in Virtual Screening. Combinatorial Chemistry \& High Throughput Screening. 2009; 12:332-43. [PubMed: 19442063]

131. Meyer MJ, Das J, Wang X, Yu H. INstruct: a database of high-quality 3D structurally resolved protein interactome networks. Bioinformatics. 2013

132. Morris JH, Meng EC, Ferrin TE. Computational Tools for the Interactive Exploration of Proteomic and Structural Data. Molecular \& Cellular Proteomics. 2010; 9:1703-15. [PubMed: 20525940]

133. Mosca R, Ceol A, Aloy P. Interactome3D: adding structural details to protein networks. Nat Meth. 2013; 10:47-53.

134. Mosca R, Pons C, Fernandez-Recio J, Aloy P. Pushing structural information into the yeast interactome by high-throughput protein docking experiments. PLoS Comput Biol. 2009; 5:e1000490. [PubMed: 19714207]

135. Mukherjee S, Zhang Y. Protein-Protein Complex Structure Predictions by Multimeric Threading and Template Recombination. Structure (London, England: 1993). 2011; 19:955-66.

136. Muley VY, Ranjan A. Evaluation of Physical and Functional Protein-Protein Interaction Prediction Methods for Detecting Biological Pathways. PLoS ONE. 2013; 8:e54325. [PubMed: 23349851]

137. Muller F-J, Laurent LC, Kostka D, Ulitsky I, Williams R, et al. Regulatory networks define phenotypic classes of human stem cell lines. NATURE. 2008; 455:401-05. [PubMed: 18724358]

138. Ochoa D, Garcia-Gutierrez P, Juan D, Valencia A, Pazos F. Incorporating information on predicted solvent accessibility to the co-evolution-based study of protein interactions. Molecular Biosystems. 2013; 9:70-76. [PubMed: 23104128]

139. Overbeek R, Fonstein M, D’Souza M, Pusch GD, Maltsev N. The use of gene clusters to infer functional coupling. Proceedings of the National Academy of Sciences. 1999; 96:2896-901.

140. Pancaldi V, Saraç ÖS, Rallis C, McLean JR, Převorovský M, et al. Predicting the Fission Yeast Protein Interaction Network. G3: Genes|Genomes|Genetics. 2012; 2:453-67.

141. Pawson T, Linding R. Network medicine. FEBS Letters. 2008; 582:1266-70. [PubMed: 18282479] 
142. Pellegrini M, Marcotte EM, Thompson MJ, Eisenberg D, Yeates TO. Assigning protein functions by comparative genome analysis: protein phylogenetic profiles. Proceedings of the National Academy of Sciences of the United States of America. 1999; 96:4285-8. [PubMed: 10200254]

143. Petrey D, Honig B. Is protein classification necessary? Toward alternative approaches to function annotation. Current Opinion in Structural Biology. 2009; 19:363-68. [PubMed: 19269161]

144. Pieper U, Webb BM, Barkan DT, Schneidman-Duhovny D, Schlessinger A, et al. ModBase, a database of annotated comparative protein structure models, and associated resources. Nucleic Acids Research. 2011; 39:D465-D74. [PubMed: 21097780]

145. Pruitt KD, Tatusova T, Maglott DR. NCBI reference sequences (RefSeq): a curated nonredundant sequence database of genomes, transcripts and proteins. Nucleic Acids Research. 2007; 35:D61-D65. [PubMed: 17130148]

146. Pujol A, Mosca R, Farrés J, Aloy P. Unveiling the role of network and systems biology in drug discovery. Trends in Pharmacological Sciences. 2010; 31:115-23. [PubMed: 20117850]

147. Rana J, Sreejith R, Gulati S, Bharti I, Jain S, Gupta S. Deciphering the host-pathogen protein interface in chikungunya virus-mediated sickness. Archives of Virology. 2013; 158:1159-72. [PubMed: 23334837]

148. Reguly T, Breitkreutz A, Boucher L, Breitkreutz BJ, Hon GC, et al. Comprehensive curation and analysis of global interaction networks in Saccharomyces cerevisiae. Journal of Biology. 2006; 5:11. [PubMed: 16762047]

149. Russell RB, Aloy P. Targeting and tinkering with interaction networks. Nature Chemical Biology. 2008; 4:666-73.

150. Sato T, Yamanishi Y, Kanehisa M, Toh H. The inference of protein-protein interactions by coevolutionary analysis is improved by excluding the information about the phylogenetic relationships. Bioinformatics. 2005; 21:3482-89. [PubMed: 15994190]

151. Schadt EE. Molecular networks as sensors and drivers of common human diseases. NATURE. 2009; 461:218-23. [PubMed: 19741703]

152. Schaefer MH, Fontaine J-F, Vinayagam A, Porras P, Wanker EE, Andrade-Navarro MA. HIPPIE: Integrating Protein Interaction Networks with Experiment Based Quality Scores. PLoS ONE. 2012; 7:e31826. [PubMed: 22348130]

153. Schwede T, Kopp J, Guex N, Peitsch MC. SWISS-MODEL: An automated protein homologymodeling server. Nucleic Acids Research. 2004; 31:3381-85. [PubMed: 12824332]

154. Shindyalov IN, Bourne PE. An alternative view of protein fold space. Prot: Struct Func Gen. 2000; 38:247-60.

155. Shoemaker B, Panchenko A. Deciphering protein-protein interactions. Part II. Computational methods to predict protein and domain interaction partners. PLoS computational biology. 2007; 3:e43. [PubMed: 17465672]

156. Shoemaker BA, Panchenko AR. Deciphering protein-protein interactions. Part I. Experimental techniques and databases. PLoS computational biology. 2007; 3:e42. [PubMed: 17397251]

157. Shoemaker BA, Zhang D, Tyagi M, Thangudu RR, Fong JH, et al. IBIS (Inferred Biomolecular Interaction Server) reports, predicts and integrates multiple types of conserved interactions for proteins. Nucleic Acids Research. 2012; 40:D834-D40. [PubMed: 22102591]

158. Singh R, Park D, Xu J, Hosur R, Berger B. Struct2Net: a web service to predict protein-protein interactions using a structure-based approach. Nucleic Acids Research. 2010; 38:W508-W15. [PubMed: 20513650]

159. Sprinzak E, Margalit H. Correlated sequence-signatures as markers of protein-protein interaction. Journal of Molecular Biology. 2001; 311:681-92. [PubMed: 11518523]

160. Sprinzak E, Sattath S, Margalit H. How reliable are experimental protein-protein interaction data? Journal of Molecular Biology. 2003; 327:919-23. [PubMed: 12662919]

161. Stein A, Russell RB, Aloy P. 3did: interacting protein domains of known three-dimensional structure. Nucleic acids research. 2005; 33:D413-7. [PubMed: 15608228]

162. Tan S-L, Ganji G, Paeper B, Proll S, Katze MG. Systems biology and the host response to viral infection. Nat Biotech. 2007; 25:1383-89. 
163. Tuncbag N, Gursoy A, Nussinov R, Keskin O. Predicting protein-protein interactions on a proteome scale by matching evolutionary and structural similarities at interfaces using PRISM. Nat Protocols. 2011; 6:1341-54.

164. Tuncbag N, Kar G, Gursoy A, Keskin O, Nussinov R. Towards inferring time dimensionality in protein-protein interaction networks by integrating structures: the p53 example. Molecular Biosystems. 2009; 5:1770-78. [PubMed: 19585003]

165. Turinsky AL, Razick S, Turner B, Donaldson IM, Wodak SJ. Literature curation of protein interactions: measuring agreement across major public databases. Database 2010. 2010 Article ID baq26.

166. Tyagi M, Hashimoto K, Shoemaker BA, Wuchty S, Panchenko AR. Large-scale mapping of human protein interactome using structural complexes. EMBO Reports. 2012; 13:266-71. [PubMed: 22261719]

167. Uhlén M, Björling E, Agaton C, Szigyarto CA-K, Amini B, et al. A Human Protein Atlas for Normal and Cancer Tissues Based on Antibody Proteomics. Molecular \& Cellular Proteomics. 2005; 4:1920-32. [PubMed: 16127175]

168. Ulitsky I, Krishnamurthy A, Karp RM, Shamir R. DEGAS: De Novo Discovery of Dysregulated Pathways in Human Diseases. PLoS ONE. 2010; 5:e13367. [PubMed: 20976054]

169. Valente GT, Acencio ML, Martins C, Lemke N. The Development of a Universal In Silico Predictor of Protein-Protein Interactions. PLoS ONE. 2013; 8:e65587. [PubMed: 23741499]

170. van Laarhoven T, Nabuurs SB, Marchiori E. Gaussian interaction profile kernels for predicting drug-target interaction. Bioinformatics. 2011

171. Vandin F, Upfal E, Raphael BJ. De novo discovery of mutated driver pathways in cancer. Genome Research. 2012; 22:375-85. [PubMed: 21653252]

172. Vidal M, Cusick Michael E, Barabási A-L. Interactome Networks and Human Disease. Cell. 2011; 144:986-98. [PubMed: 21414488]

173. Vogelstein B, Papadopoulos N, Velculescu VE, Zhou S, Diaz LA, Kinzler KW. Cancer Genome Landscapes. Science. 2013; 339:1546-58. [PubMed: 23539594]

174. von Mering C, Krause R, Snel B, Cornell M, Oliver SG, et al. Comparative assessment of largescale data sets of protein-protein interactions. NATURE. 2002; 417:399-403. [PubMed: 12000970]

175. Wale N. Machine Learning in Drug Discovery and Development. Drug Development Research. 2011; 72:112-19.

176. Wang K, Nemenmann I, Banerjee N, Margolin A, Califano A. Genome-wide discovery of modulators of transcriptional interactions in human B lymphocytes. Lecture Notes in Computer Science. 2006; 3909:348-62.

177. Wang K, Saito M, Bisikirska BC, Alvarez MJ, Lim WK, et al. Genome-wide identification of post-translational modulators of transcription factor activity in human B cells. Nat Biotech. 2009; 27:829-37.

178. Wang X, Wei X, Thijssen B, Das J, Lipkin SM, Yu H. Three-dimensional reconstruction of protein networks provides insight into human genetic disease. Nat Biotech. 2012; 30:159-64.

179. Wass MN, Fuentes G, Pons C, Pazos F, Valencia A. Towards the prediction of protein interaction partners using physical docking. Mol Syst Biol. 2011; 7

180. Witte JS. Genome-Wide Association Studies and Beyond. Annual Review of Public Health. 2010; 31:9-20.

181. Xie L, Xie L, Bourne PE. Structure-based systems biology for analyzing off-target binding. Current Opinion in Structural Biology. 2011; 21:189-99. [PubMed: 21292475]

182. Xu Q, Dunbrack RL. The protein common interface database (ProtCID) - a comprehensive database of interactions of homologous proteins in multiple crystal forms. Nucleic Acids Research. 2011; 39:D761-D70. [PubMed: 21036862]

183. Xu Q, Xiang EW, Yang Q. Transferring network topological knowledge for predicting proteinprotein interactions. Proteomics. 2011; 11:3818-25. [PubMed: 21770035]

184. Yabuuchi H, Niijima S, Takematsu H, Ida T, Hirokawa T, et al. Analysis of multiple compoundprotein interactions reveals novel bioactive molecules. Mol Syst Biol. 2011; 7 
185. Yildirim MA, Goh K-I, Cusick ME, Barabasi A-L, Vidal M. Drug-target network. Nat Biotech. 2007; 25:1119-26.

186. You Z-H, Lei Y-K, Zhu L, Xia J, Wang B. Prediction of protein-protein interactions from amino acid sequences with ensemble extreme learning machines and principal component analysis. BMC Bioinformatics. 2013; 14:S10. [PubMed: 23815620]

187. Yousef A, Moghadam Charkari N. A novel method based on new adaptive LVQ neural network for predicting protein-protein interactions from protein sequences. Journal of Theoretical Biology. 2013

188. Yu C-Y, Chou L-C, Chang D. Predicting protein-protein interactions in unbalanced data using the primary structure of proteins. BMC Bioinformatics. 2010; 11:167. [PubMed: 20361868]

189. Yu X, Wallqvist A, Reifman J. Inferring high-confidence human protein-protein interactions. BMC Bioinformatics. 2012; 13:79. [PubMed: 22558947]

190. Zahiri J, Yaghoubi O, Mohammad-Noori M, Ebrahimpour R, Masoudi-Nejad A. PPIevo: Proteinprotein interaction prediction from PSSM based evolutionary information. Genomics. 2013

191. Zaman A, Rahaman MH, Razzaque S. Kaposi's sarcoma: A computational approach through protein-protein interaction and gene regulatory networks analysis. Virus Genes. 2013; 46:24254. [PubMed: 23266878]

192. Zhang KX, Ouellette BFF. CAERUS: Predicting CAncER oUtcomeS Using Relationship between Protein Structural Information, Protein Networks, Gene Expression Data, and Mutation Data. PLoS Comput Biol. 2011; 7:e1001114. [PubMed: 21483478]

193. Zhang L, Li S, Hao C, Hong G, Zou J, et al. Extracting a few functionally reproducible biomarkers to build robust subnetwork-based classifiers for the diagnosis of cancer. Gene. 2013; 526:232-38. [PubMed: 23707927]

194. Zhang QC, Petrey D, Deng L, Qiang L, Shi Y, et al. Structure-based prediction of protein-protein interactions on a genome-wide scale. NATURE. 2012; 490:556-60. [PubMed: 23023127]

195. Zhang QC, Petrey D, Garzón JI, Deng L, Honig B. PrePPI: a structure-informed database of protein-protein interactions. Nucleic Acids Research. 2013; 41:D828-D33. [PubMed: 23193263]

196. Zhang QC, Petrey D, Norel R, Honig BH. Protein interface conservation across structure space. Proc Natl Acad Sci U S A. 2010; 107:10896-901. [PubMed: 20534496]

197. Zhang Y, Hubner IA, Arakaki AK, Shakhnovich E, Skolnick J. On the origin and highly likely completeness of single-domain protein structures. Proceedings of the National Academy of Sciences of the United States of America. 2006; 103:2605-10. [PubMed: 16478803]

198. Zhu J, Zhang B, Smith EN, Drees B, Brem RB, et al. Integrating large-scale functional genomic data to dissect the complexity of yeast regulatory networks. Nat Genet. 2008; 40:854-61. [PubMed: 18552845]

199. Zimmermann GR, Lehár J, Keith CT. Multi-target therapeutics: when the whole is greater than the sum of the parts. Drug Discovery Today. 2007; 12:34-42. [PubMed: 17198971] 


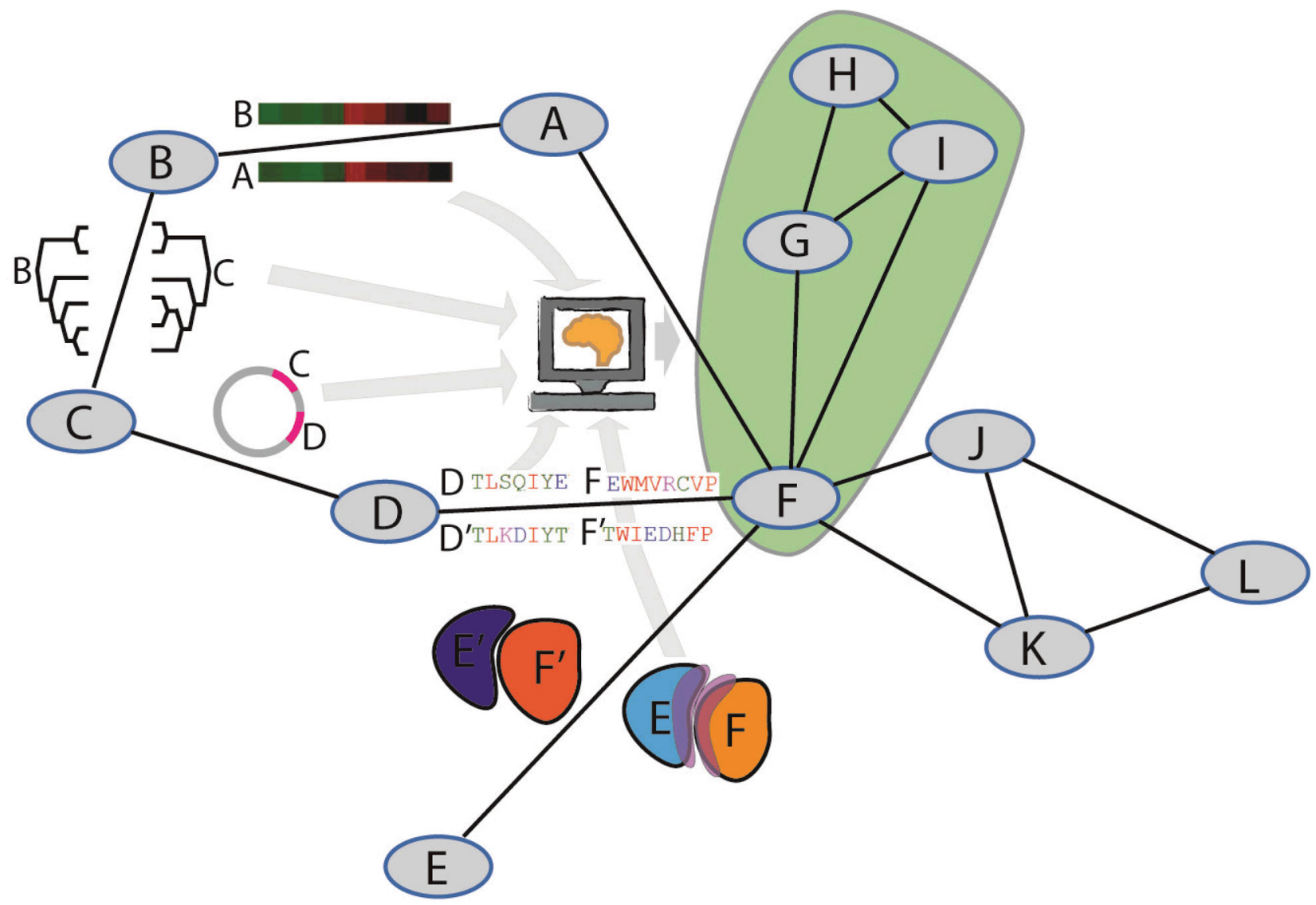

Figure 1. Constructing interactomes with different types of evidence

Nodes $\mathrm{A}$ to $\mathrm{L}$ in the figure represent proteins and the edges between them represent physical interactions. Edges can be predicted using evidence such as co-expression (A,B), similarity in evolutionary history $(B, C)$, proximity of their corresponding genes in different genomes (C,D). Databases of experimentally verified interactions in modeled organisms can also be used to predict interactions in other organisms including sequence similarity to two other proteins known to interact ( $\mathrm{D}$ and $\mathrm{F}$ are sequence similar to a known interaction between $\mathrm{D}^{\prime}$ and $\mathrm{C}^{\prime}$ ), and structural similarity ( $\mathrm{E}$ and $\mathrm{F}$ are structurally similar to $\mathrm{E}^{\prime}$ and $\mathrm{F}^{\prime}$ and, indicated in purple, the interface modeled for proteins $\mathrm{E}$ and $\mathrm{F}$ display properties similar to those of known interfaces). The different types of evidence can also be combined using machine learning approaches to infer physical interactions or to infer functional or disease-associated "modules" in the network (shaded green). 